\title{
Tumor-associated macrophages (TAMs): clinical-pathological parameters in squamous cell carcinomas of the lower lip
}

\section{Priscilla Suassuna Carneiro LÚCIO(a) Daniela Cotta RIBEIRO(b) \\ Maria Cássia Ferreira de AGUIAR ${ }^{(b)}$ Pollianna Muniz ALVES(a) \\ Cassiano Francisco Weege \\ NONAKA ${ }^{(a)}$ \\ Gustavo Pina GODOY(c)}

(a) Universidade Estadual da Paraíba - UEPB, Department of Dentistry, Campina Grande, PB, Brazil.

(b) Universidade Federal de Minas Gerais - UFMG, Department of Oral Surgery and Pathology, School of Dentistry, Belo Horizonte, MG, Brazil.

(c) Universidade Federal de Pernambuco - UFPE, Department of Pathology, Recife, PE, Brazil.

Declaration of Interests: The authors certify that they have no commercial or associative interest that represents a conflict of interest in connection with the manuscript.

\section{Corresponding Author:}

Gustavo Pina Godoy

E-mail: gruiga@hotmail.com

DOI: 10.1590/1807-3107BOR-2016.vol30.0095

Submitted: Sep 01, 2015

Accepted for publication: Apr 25, 2016

Last revision: June 07, 2016
Abstract: The objective of this study was to analyze the presence of tumor-associated macrophage (TAM) subpopulations M1 and M2 in squamous cell carcinoma of the lower lip (SCCLL) by immunohistochemitry, and to evaluate the possible role of these subtypes in the development of regional lymph node metastasis and their association with clinical and pathological parameters. Forty-two cases of SCCLL were divided into two groups (21 with and 21 without regional lymph node metastasis). The histopathological grade of malignancy was determined and the material was submitted to double staining with anti-CD68/anti-CD163 and anti-CD68/anti-HLA-DR monoclonal antibodies. The results were analyzed statistically using the Wilcoxon signed-rank and Spearman correlation tests. The M1 and M2 subpopulations were observed in all cases studied. No significant difference was observed between the quantities of M1 and M2 TAMs regarding tumor size ( $p>0.05)$. A significantly larger number of M2 compared to M1 TAMs was observed in tumors without regional lymph node metastasis, tumors in early stages, and low-grade tumors $(p<0.05)$. No significant difference between the numbers of M1 and M2 TAMs was observed in tumors with regional lymph node metastasis, tumors in advanced stages, and high-grade tumors $(p>0.05)$. There was a positive weak correlation between M1 and M2 TAMs $(r=0.361 ; p=0.019)$. The results suggest a more important role of M2 TAMs in early stages than advanced stages of lip carcinogenesis. The progression of SCCLL does not seem to be related to an imbalance of macrophage polarization in the microenvironment of these tumors.

Keywords: Lip; Carcinoma, Squamous Cell; Immunohistochemistry.

\section{Introduction}

Squamous cell carcinoma is the most common malignant tumor affecting the lower lip. ${ }^{1}$ Although its pathogenesis is not fully understood, unprotected chronic exposure to ultraviolet radiation is the main factor associated with the development of this neoplasm. ${ }^{2,3,4,5}$

Although squamous cell carcinoma of the lower lip (SCCLL) is easily visualized, the first signs of occurrence of this tumor are usually neglected. Since most tumors are diagnosed in a more advanced stage and in the presence of regional lymph node metastases, their prognoses are poor. ${ }^{6,7,8}$ Also, components of the tumor microenvironment are directly related to the prognosis of SCCLL. Although inflammatory 
cells usually favor tissue repair, they may assume a dual role at the time when neoplastic cells are able to divert natural inflammatory activities for tumor growth and invasion. $.10,11$

Macrophages are the main defense cells in the tumor microenvironment. Tumor-associated macrophages (TAMs) can be recognized phenotypically by two types of polarization: M1 and M2. The M1 phenotype, which is a classic macrophage activation, possesses proinflammatory properties, maintaining constantly elevated levels of cytokines such as interleukin 12 (IL-12), IL-23, and interferon gamma (IFN-ץ). Additionally, M1 TAMs are able to destroy neoplastic cells by releasing reactive oxygen species. On the other hand, the M2 subtype, which corresponds to alternative macrophage activation, possesses molecular characteristics that permit neoplastic cells to escape immune surveillance. This immunosuppressive capacity is a consequence of the production of anti-inflammatory and immunosuppressive cytokines such as IL-10 and transforming growth factor beta (TGF- $\beta$ ), inhibition of the inflammatory and cytotoxic functions of M1 macrophages, and induction of angiogenesis and tissue remodeling and repair, conditions that favor tumor growth and dissemination. $12,13,14,15,16,17,18,19,20,21,22$

Although studies have suggested a significant association between TAMs and poor prognosis in patients with oral squamous cell carcinoma (OSCC), ${ }^{14,15,23,24,25,26}$ little is known about these macrophage phenotypes in SCCLL. Therefore, the objective of the present study was to investigate the presence of TAM subpopulations M1 and M2 in cases of SCCLL and to evaluate the possible role of these subtypes in the development of regional lymph node metastasis and their association with clinical and pathological features of the tumor.

\section{Methodology}

This was a retrospective study comprising the period from 2002 to 2012. The study was conducted in accordance with ethical guidelines and with the Declaration of Helsinki of 1975/1983 and was approved by the local ethics committee (Protocol No. 0202.0.133.000-12).

\section{Specimens}

Forty-two cases of SCCLL obtained from the archives of the Napoleão Laureano Hospital, João Pessoa, Paraíba, Brazil, between January 2002 and June 2012, were selected for this study. The sample was then divided into 21 cases with regional lymph node metastasis and 21 cases without metastasis. Only SCCLL specimens obtained from surgical resections, whose paraffin blocks contained a sufficient quantity and quality of biological material for histopathological and immunohistochemical analyses, were included in the sample. Cases of recurrent tumors, patients previously submitted to chemotherapy and/or radiation therapy, and cases with incomplete clinical data (gender, age, tumor size/extent, presence of regional lymph node and distant metastases, and clinical stage) were excluded. The parameters of the 6 th edition of the TNM Classification of Malignant Tumors were used for clinical staging. ${ }^{27}$

\section{Histopathological analysis}

The selected sample, fixed in $10 \%$ formalin and embedded in paraffin, was cut into $5-\mu \mathrm{m}$ thick sections. These sections were mounted on to clean glass slides and submitted to routine staining with hematoxylin-eosin. The SCCLL specimens were examined under a light microscope (Leica DM500, Leica Microsystems Vertrieb GmbH, Wetzlar, Germany) at $100 \times$ and $400 \times$ magnification. The histopathological grade of malignancy was evaluated at the invasive front of the tumor according to the system proposed by Bryne. ${ }^{28}$ Two previously trained examiners who were unaware of the clinical data performed the analyses. The Bryne system consists in attributing scores to the following parameters: degree of keratinization, pattern of invasion, nuclear pleomorphism, and inflammatory infiltrate. The scores are summed to obtain the final score of malignancy for each case. According to da Silveira et al., ${ }^{29}$ tumors with a final score $\leq 8$ were classified as low grade of malignancy and tumors with a final score $\geq 9$ were classified as high grade of malignancy. A consensus reading was obtained for discordant cases. 


\section{Immunohistochemical analysis}

The selected sample, fixed in $10 \%$ formalin and embedded in paraffin, was cut into $3 \mu \mathrm{m}$ thick sections and the sections were mounted on to clean, defatted, and silanized glass slides. The tissue sections were deparaffinized and immersed in 3\% hydrogen peroxide to block endogenous peroxidase. Next, the sections were washed in phosphate-buffered saline (PBS) and submitted to dextran polymer-based immunohistochemistry (EnVision ${ }^{\mathrm{TM}} \mathrm{G} / 2$ Doublestain System, Dako North America, Inc., Carpinteria, CA, USA) using double staining with anti-CD68, anti-CD163, and anti-HLA-DR monoclonal antibodies (Table 1). The reaction was developed with $\mathrm{DAB}+$ for the $\mathrm{CD} 68$ antibody, which resulted in brown cytoplasmic staining, and with Permanent Red for CD163 and HLA-DR, which resulted in red cytoplasmic staining. Finally, the sections were counterstained with Mayer's hematoxylin and mounted with a coverslip. Samples of periapical granulomas were used as positive controls for the anti-CD68, anti-HLA-DR, and anti-CD163 antibodies. The negative control consisted of replacement of the primary antibody with $1 \%$ bovine serum albumin in buffer.

\section{Cell count}

The TAM subpopulations were analyzed quantitatively according to the method of Ma et al. ${ }^{17}$ At $100 x$ magnification (Leica DM500, Leica Microsystems Vertrieb GmbH, Wetzlar, Germany), 10 fields showing highest immunoreactivity to the anti-CD68/anti-HLA-DR and anti-CD68/anti-CD163 antibodies were selected along the invasive front of the tumor. Each of these fields was photographed at 400x magnification (Carl Zeiss ${ }^{\circledR}$ Axiolab light microscope, AxioCam MRC, and Axiovision Rel 4.8.2 software; Acer ${ }^{\circledR}$ Aspire One 722 computer). Only cells exhibiting simultaneous brown-red staining for CD68/HLA-DR (M1 TAMs) and CD68/CD163 (M2 TAMs) were counted in each field using the Image $₫$ program (Image Processing and Analysis in Java, National Institute of Mental Health, Bethesda, MD, USA). The values obtained for each field were summed and the total number of cells exhibiting CD68/HLA-DR and CD68/CD163 double staining was established. The latter was used to calculate the mean number of M1 and M2 macrophages per case.

\section{Statistical analysis}

The results were analyzed using the Statistical Package for the Social Sciences (version 17.0; SPSS, Inc., Chicago, IL, USA). Descriptive statistics was used for characterization of the sample.

Analysis of the number of M1 and M2 TAMs by the Kolmogorov-Smirnov test revealed the absence of a normal distribution. Therefore, the nonparametric Wilcoxon signed-rank test was used to compare median numbers of M1 and M2 TAMs according to the different clinical pathological parameters analyzed. For statistical purposes, tumors classified as T2, T3, and T4 were combined into a single group. Similarly, cases exhibiting regional lymph node metastasis (N1 and N2) were combined into a single group. With respect to clinical staging, the cases were grouped as follows: early stage (I and II) and advanced stage (III and IV). Spearman's correlation test was used to determine possible correlations between the number of M1 and

Table 1. Clone, specificity, company, dilution, antigen retrieval, and incubation of the primary antibodies.

\begin{tabular}{|c|c|c|c|c|c|}
\hline Clone & Specificity & Company & Dilution & Antigen retrieval & Incubation \\
\hline PG-M1 & CD68 & Dako, Carpinteria, CA & $1: 1500$ & $\begin{array}{c}\text { Citrate, } \mathrm{pH} 6.0 \text {, water bath, } \\
95^{\circ} \mathrm{C}, 30 \mathrm{~min}\end{array}$ & $60 \mathrm{~min}$ \\
\hline $10 D 6$ & CD163 & Novocastra Laboratories, Newcastle Upon Tyne, UK & $1: 200$ & $\begin{array}{c}\text { Citrate, } \mathrm{pH} 6.0 \text {, water bath, } \\
95^{\circ} \mathrm{C}, 30 \mathrm{~min}\end{array}$ & $60 \mathrm{~min}$ \\
\hline TAL.1B5 & HLA-DR & Dako, Carpinteria, CA & $1: 800$ & $\begin{array}{c}\text { Citrate, } \mathrm{pH} 6.0 \text {, water bath, } \\
95^{\circ} \mathrm{C}, 30 \mathrm{~min}\end{array}$ & $60 \mathrm{~min}$ \\
\hline
\end{tabular}


Tumor-associated macrophages (TAMs): clinical-pathological parameters in squamous cell carcinomas of the lower lip

M2 macrophages in SCCLL. A level of significance of $5 \%(\mathrm{p}<0.05)$ was adopted for all tests.

\section{Results}

\section{Clinical and morphological analysis}

The clinical and histopathological characteristics of the sample are shown in Table 2.

\section{Immunohistochemical analysis}

Analysis of M1 TAMs along the invasive front revealed the presence of these cells in all SCCLL cases studied. The mean number ranged from 14.1 to 54.6 (Figures 1A and 1B). Similarly, all SCCLL cases exhibited M2 TAMs, with mean numbers ranging from 12.4 to 85.6 (Figures 2A and 2B).

With respect to tumor size, the median number of M1 and M2 macrophages in T1 tumors was 26.2 (range: 18.1 to 38.9 ) and 28.9 (range: 18.0 to 48.6 ), respectively. In T2-T4 tumors, the median number of M1 and M2 macrophages was 33.1 (range: 14.1 to 54.6) and 35.4 (range: 12.4 to 85.6), respectively. The Wilcoxon signed-rank test revealed no significant difference between the quantities of M1 and M2 TAMs regarding tumor size/extent $(p>0.05)$ (Table 3; Figure 3).

Regarding regional lymph node metastasis, the median number of M1 and M2 macrophages in N0 tumors was 26.8 (range: 14.1 to 54.6 ) and 37.3
Table 2. Distribution of cases of lower lip squamous cell carcinoma according to clinicopathological characteristics.

\begin{tabular}{|c|c|}
\hline Characteristics & n (\%) \\
\hline \multicolumn{2}{|l|}{ Gender } \\
\hline Male & $33(78.6)$ \\
\hline Female & $9(21.4)$ \\
\hline \multicolumn{2}{|l|}{ Tumor } \\
\hline $\mathrm{T} 1$ & $13(31.0)$ \\
\hline T2 & $24(57.1)$ \\
\hline T3 & $4(9.5)$ \\
\hline $\mathrm{T} 4$ & $1(2.4)$ \\
\hline \multicolumn{2}{|l|}{ Node } \\
\hline NO & $21(50.0)$ \\
\hline $\mathrm{N} 1$ & $17(40.5)$ \\
\hline N2 & $4(9.5)$ \\
\hline N3 & $0(0.0)$ \\
\hline \multicolumn{2}{|l|}{ Metastasis } \\
\hline MO & $42(100.0)$ \\
\hline Ml & $0(0.0)$ \\
\hline \multicolumn{2}{|l|}{ Clinical stage } \\
\hline Stage I & $8(19.0)$ \\
\hline Stage II & $13(31.0)$ \\
\hline Stage III & $16(38.1)$ \\
\hline Stage IV & $5(11.9)$ \\
\hline \multicolumn{2}{|c|}{ Histopathological grade } \\
\hline Low-grade & $14(33.3)$ \\
\hline High-grade & $28(66.7)$ \\
\hline
\end{tabular}

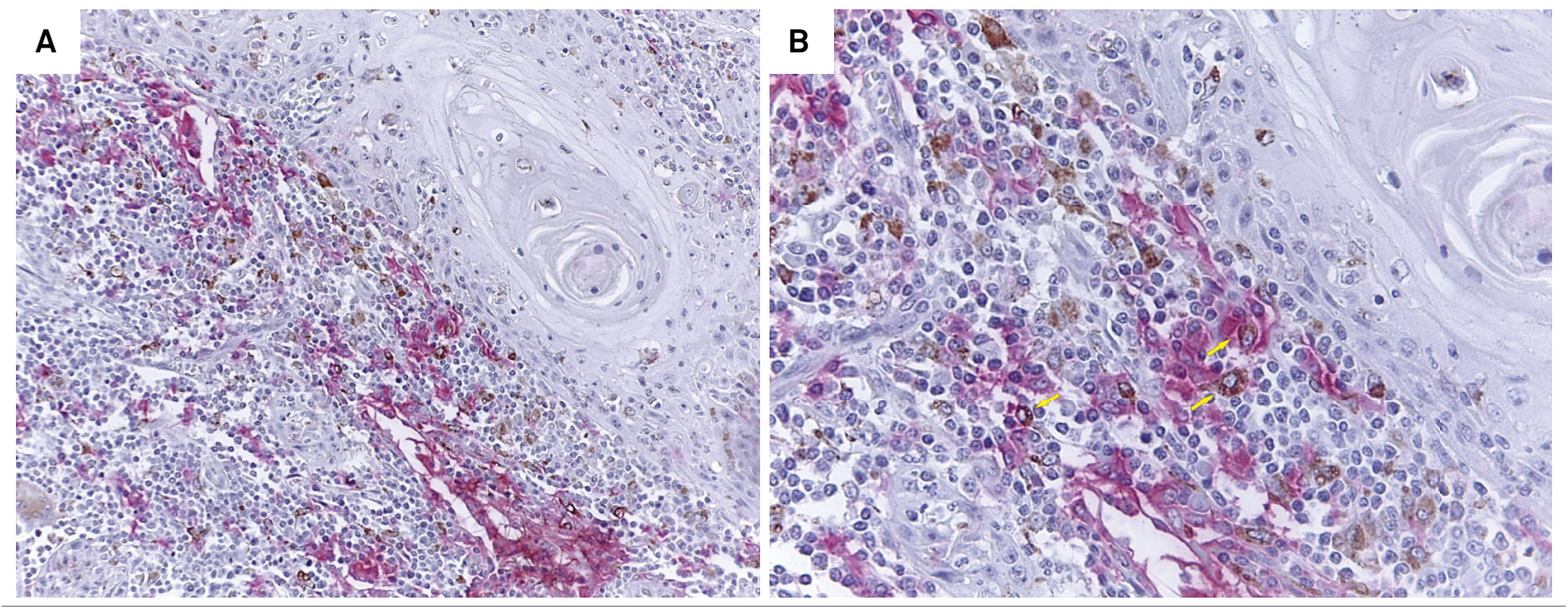

Figure 1. (A) Invasive front of SCCLL exhibiting CD68+ (brown staining) and HLA-DR+ (red staining) cells (EnVision, 200 $\times$ ). (B) M1 TAMs (arrows) double stained with anti-CD68 and anti-HLA-DR antibodies (EnVision, 400×). 


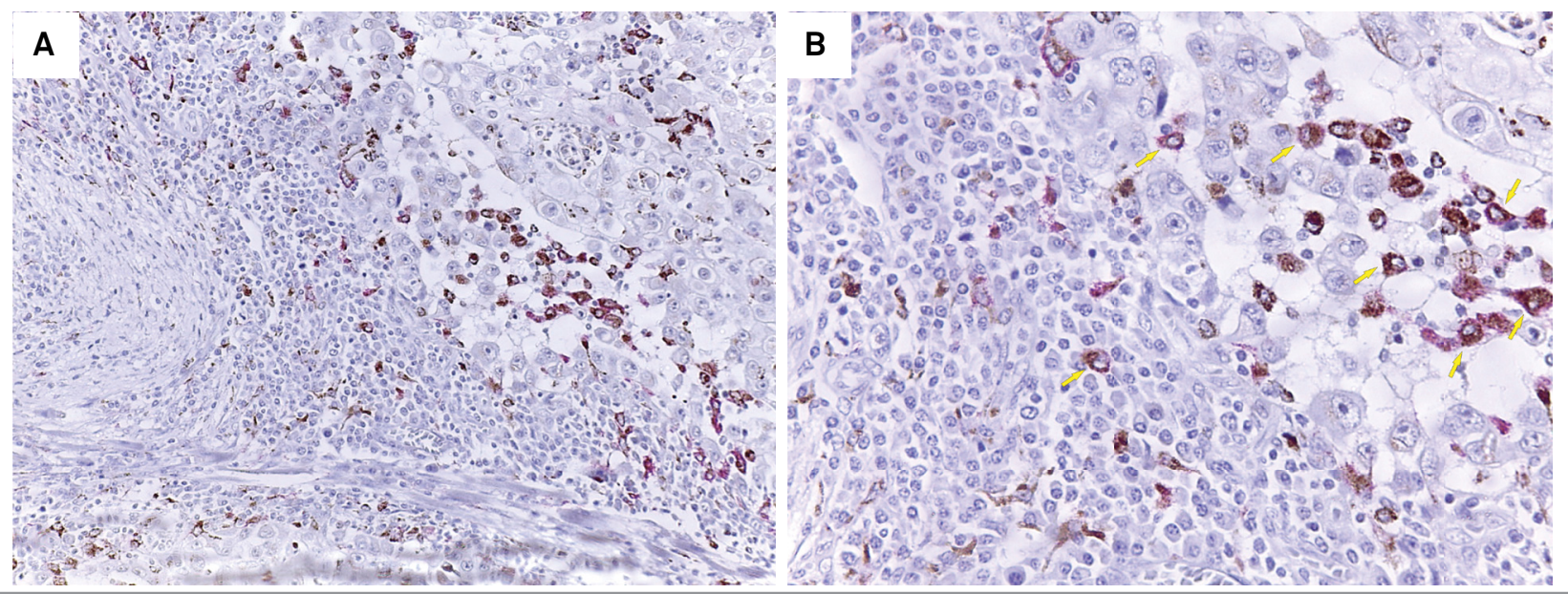

Figure 2. (A) Invasive front of SCCLL exhibiting CD68+ (brown staining) and CD163+ (red staining) cells (EnVision, 200 $\times$ ). (B) M2 TAMs (arrows) double stained with anti-CD68 and anti-CD163 antibodies (EnVision, 400×).
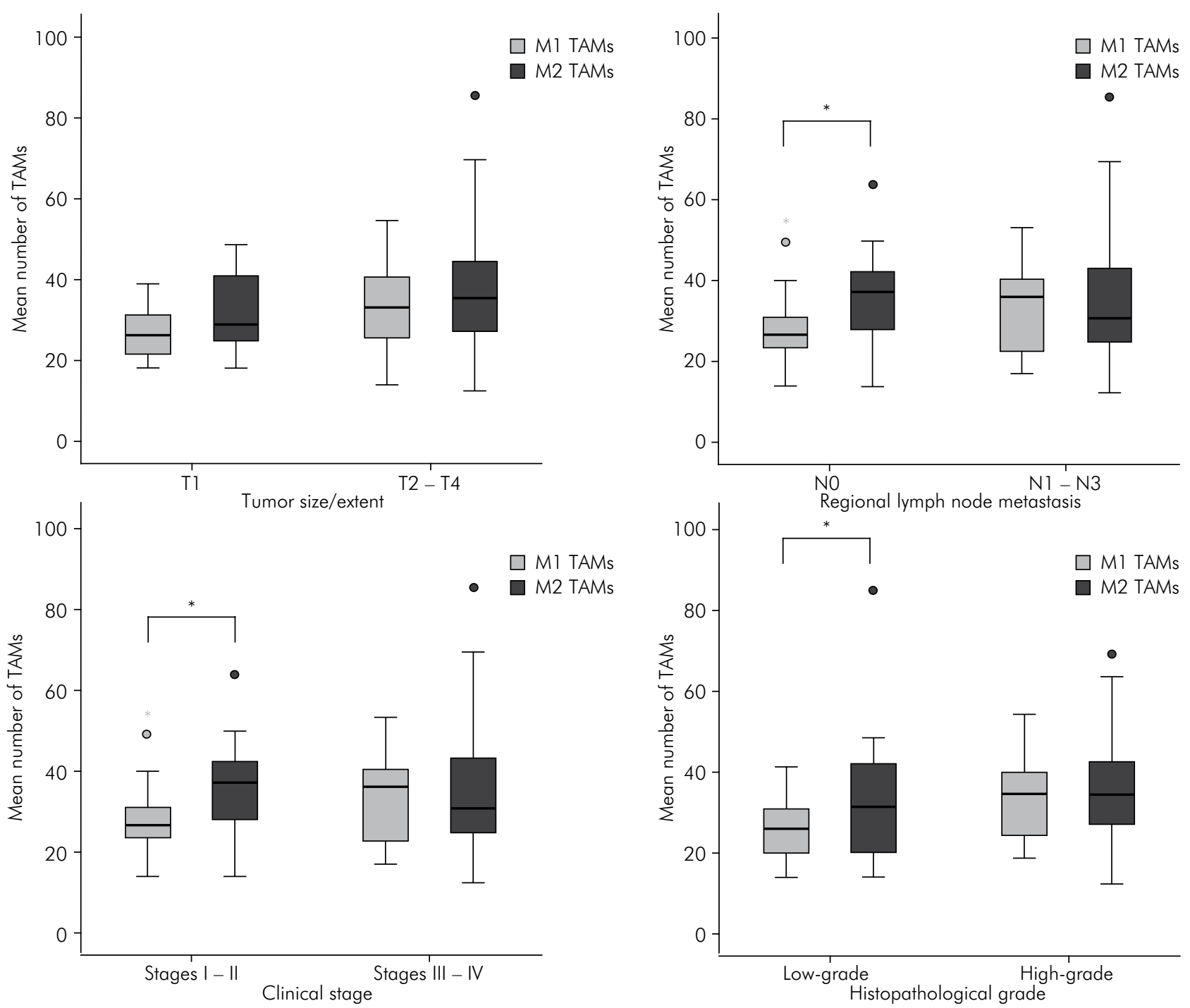

Figure 3. Box plot charts illustrating the number of M1 and M2 TAMs in SCCLLs according to tumor size/ extent, regional lymph node metastasis, clinical stage, and histopathological grade of malignancy. *Statistical difference $(p<0.05$; Wilcoxon signed rank test). 
- Tumor-associated macrophages (TAMs): clinical-pathological parameters in squamous cell carcinomas of the lower lip

Table 3. Distribution of cases of lower lip squamous cell carcinoma according to ranks of M1 and M2 TAMs [n (\%)] and clinicopathological characteristics.

\begin{tabular}{|c|c|c|c|c|}
\hline Characteristics & M1 TAMs > M2 TAMs & M1 TAMs $<$ M2 TAMs & M1 TAMs $=$ M2 TAMs & $p$-value* \\
\hline \multicolumn{5}{|l|}{ Tumor size } \\
\hline $\operatorname{T1}(n=13)$ & $3(23.1)$ & $10(76.9)$ & $0(0.0)$ & 0.133 \\
\hline $\mathrm{T} 2-\mathrm{T} 4(\mathrm{n}=29)$ & $12(41.4)$ & $17(58.6)$ & $0(0.0)$ & 0.173 \\
\hline \multicolumn{5}{|l|}{ Nodal metastasis } \\
\hline $\mathrm{NO}(\mathrm{n}=21)$ & $5(23.8)$ & $16(76.2)$ & $0(0.0)$ & 0.009 \\
\hline$N 1-N 2(n=21)$ & $10(47.6)$ & $11(52.4)$ & $0(0.0)$ & 0.958 \\
\hline \multicolumn{5}{|l|}{ Clinical stage } \\
\hline$I-\|(n=21)$ & $5(23.8)$ & $16(76.2)$ & $0(0.0)$ & 0.009 \\
\hline$I I I-I V(n=21)$ & $10(47.6)$ & $11(52.4)$ & $0(0.0)$ & 0.958 \\
\hline \multicolumn{5}{|l|}{ Histopathological grade } \\
\hline Low-grade $(n=14)$ & $4(28.6)$ & $10(71.4)$ & $0(0.0)$ & 0.048 \\
\hline High-grade $(n=28)$ & 11 (39.3) & $17(60.7)$ & $0(0.0)$ & 0.480 \\
\hline
\end{tabular}

* Wilcoxon signed rank test.

(range: 14.1 to 64.0 ), respectively. In N1-N2 tumors, the median number of M1 and M2 macrophages was 36.2 (range: 17.1 to 53.4 ) and 30.9 (range: 12.4 to 85.6), respectively. The Wilcoxon signed-rank test revealed a significantly larger number of M2 compared to M1 TAMs in N0 tumors ( $p=0.009$ ) (Table 3; Figure 3). On the other hand, no significant difference between the numbers of M1 and M2 TAMs was observed in N1-N2 tumors $(\mathrm{p}=0.958)$ (Table 3; Figure 3).

Since no distant metastases were identified in any of the 42 sampled cases, possible differences in the number of M1 and M2 TAMs related to this clinical parameter could not be analyzed statistically.

Analysis according to clinical staging showed a median number of M1 and M2 macrophages of 26.8 (range: 14.1 to 54.6 ) and 37.3 (range: 14.1 to 64.0 ), respectively, in early stage (I-II) tumors. In advanced stage (III-IV) tumors, the median number of M1 and M2 macrophages was 36.2 (range: 17.1 to 53.4) and 30.9 (range: 12.4 to 85.6 ), respectively. The Wilcoxon signed-rank test revealed a significantly larger number of M2 compared to M1 TAMs in early stage (I-II) tumors $(\mathrm{p}=0.009)$ (Table 3; Figure 3). No significant difference between the numbers of M1 and M2 TAMs was observed in advanced stage (III-IV) tumors $(p=0.958)$ (Table 3; Figure 3).
Regarding the histopathological grade of malignancy, the median number of M1 and M2 macrophages in low-grade tumors was 26.2 (range: 14.1 to 41.5 ) and 31.6 (range: 14.1 to 85.6 ), respectively. In high-grade tumors, the median number of M1 and M2 macrophages was 34.7 (range: 18.8 to 54.6) and 34.6 (range: 12.4 to 69.6 ), respectively. The Wilcoxon signed-rank test revealed a significantly larger number of M2 compared to M1 TAMs in low-grade tumors $(p=0.048)$ (Table 3; Figure 3). However, no significant difference between the numbers of M1 and M2 TAMs was observed in high-grade tumors $(\mathrm{p}=0.480)$ (Table 3; Figure 3).

Spearman's correlation test revealed a significant weak positive correlation between the number of M1 and M2 macrophages in SCCLL ( $\mathrm{r}=0.361$; $\mathrm{p}=0.019)$.

\section{Discussion}

TAMs make up most of the cellular part of the tumor microenvironment. In this respect, M2 TAMs have been shown to produce various cytokines that promote immunosuppression and favor tumor growth and progression, while M1 TAMs contribute to an effective antitumor response. ${ }^{11,12}$ Thus, the predominance of one subtype over the other may explain differences in the biological behavior 
of different neoplasms and/or in the molecular mechanisms of immune escape. . $^{1214}$

In the present study, both macrophage subtypes, M1 and M2, were detected along the invasive front in SCCLL. A predominance of M2 over M1 TAMs was observed in tumors without regional lymph node metastasis and in early-stage tumors $(p=0.009)$. Taken together, these results suggest an important role of TAMs in the microenvironment of SCCLL. The immunosuppressive activity of the M2 subpopulation may be particularly necessary in the early stages of lip carcinogenesis, in which neoplastic cells are possibly more immunogenic.

To the best of our knowledge, there are no studies associating TAM subpopulations with the development of regional metastases in SCCLL (Pubmed Database). For OSCC, Fujii et al. ${ }^{15}$ found no association between TAM infiltration and the development of regional lymph node metastasis. In contrast, using immunohistochemistry, Li et al., ${ }^{23} \mathrm{Liu}$ et al. ${ }^{24}$ and Marcus et al. ${ }^{25}$ demonstrated a significant association between TAMs and the development of clinically positive lymph nodes in oral and oropharyngeal SCC. Furthermore, Costa et al. ${ }^{14}$ observed a predominance of M2 TAMs in cases of OSCC with regional nodal metastasis when compared to OSCC without metastasis.

In line with previous observations, in a meta-analysis, Zhang et al. ${ }^{26}$ demonstrated a significant association between a high density of TAMs and more advanced stages of OSCC [RR $=1.49$ (95\%CI, 1.17-1.89)]. Fujii et al. ${ }^{15}$ detected higher concentrations of TAMs in stage III and IV OSCCs. Additionally, patients whose tumors contained larger amounts of M2 TAMs had poor survival. Taken together, these findings indicate the pro-tumor profile of M2 macrophages since this phenotype promotes angiogenesis and extracellular matrix remodeling by expressing metalloproteinases, conditions that favor neoplastic dissemination. 12,14,15,17,19,22

In contrast to previous studies on OSCC, the present results suggest that M2 TAMs may play a more important role in early stages of lip carcinogenesis. During these stages in which tumors are possibly more immunogenic, neoplastic cells may promote an immunosuppressive microenvironment in order to escape immune surveillance. This microenvironment could favor macrophage polarization to the M2 phenotype. This cell subpopulation, in turn, would contribute to this immunosuppressive environment since M2 macrophages have been shown to recruit T regulatory cells ${ }^{30}$ and to inhibit the proliferation of CD8+ T cells. ${ }^{31,32}$ In addition to their involvement in the modulation of immunoinflammatory responses in the microenvironment of SCCLL, M2 TAMs may also participate in the early stages of tumor growth through the induction of angiogenesis and extracellular matrix remodeling. ${ }^{11,12}$

The establishment of an immunosuppressive environment could be an early event in lip carcinogenesis. In line with this suggestion, Gasparoto et al. ${ }^{33}$ demonstrated the accumulation of functional $\mathrm{T}$ regulatory cells (CD4+CD25+FoxP3+) in actinic cheilitis, which is characterized by potentially malignant lesions that can progress to SCCLL. These authors also observed higher expression of IL-10 and TGF- $\beta$ and lower expression of IFN- $\gamma$ in actinic cheilitis when compared to the control group (healthy gingival tissue). ${ }^{33}$ These findings suggest the existence of a mutually reinforcing cytokine signal network between M2 TAMs and T regulatory cells in early stages of lip carcinogenesis.

In the present study, no statistically significant difference between the numbers of M1 and M2 TAMs was observed in tumors with regional lymph node metastasis and tumors in advanced stages $(p>0.05)$. Taken together, these findings suggest that progression of SCCLL is not related to an imbalance of macrophage polarization in the microenvironment of these tumors. Nevertheless, further studies involving larger samples are needed to fully establish the role of TAM subpopulations in the progression of this cancer.

Although the TNM system is used for the determination of therapeutic protocols and estimation of survival, it is not always able to establish the clinical outcome for patients with OSCC. Therefore, complementary tools are used and constantly improved to determine the prognosis of patients with these tumors. Within this context, histopathological grading of malignancy is important since more aggressive cells are found in deeper zones (tumor invasive front) and can predict the probable behavior of the tumor as a whole..$^{28,29}$ 
The histopathological malignancy grading system proposed by Bryne ${ }^{28}$ was used in the present study and an expressive number of high-grade malignant cases were observed $(n=28)$. There was a significantly larger number of M2 compared to M1 TAMs in low-grade tumors $(\mathrm{p}=0.048)$. On the other hand, there was no significant difference between the numbers of M1 and M2 TAMs in high-grade tumors $(p=0.480)$. As observed in this study, low-grade SCCLLs are early-stage tumors $(p=0.003)$ usually permeated by an intense inflammatory infiltrate. These findings again suggest that, in order to escape the antitumor immune response in early stages of lip carcinogenesis, neoplastic cells recruit a larger number of M2 macrophages to the tumor microenvironment.

The HLA-DR, CD68, and CD163 antibodies are widely used for the identification of macrophage subsets. However, these immunomarkers can also be expressed in other cell types, such as CD1a-positive immature dendritic cells (reactive to CD68), ${ }^{34}$ lymphocyte subsets and dendritic cells (reactive to HLA-DR), ${ }^{35}$ and some myeloid dendritic cells (identified by CD163) ${ }^{36}$ It is therefore postulated that double staining with the CD68/HLA-DR (M1 TAMs) or CD68/CD163 (M2

\section{References}

1. Zini A, Czerninski R, Sgan-Cohen HD. Oral cancer over four decades: epidemiology, trends, histology, and survival by anatomical sites. J Oral Pathol Med. 2010;39(4):299-305. doi:10.1111/j.1600-0714.2009.00845.x

2. Souza RL, Fonseca-Fonseca T, Oliveira-Santos CC, Corrêa GT, Santos FB, Cardoso CM et al. Lip squamous cell carcinoma in a Brazilian population: epidemiological study and clinicopathological associations. Med Oral Patol Oral Cir Bucal. 2011;16(6):e757-62. doi:10.4317/medoral.16954

3. Gutiérrez-Pascual M, Vicente-Martín FJ, Fernández-Álvarez JG, Martín-López R, Pinedo-Moraleda F, López-Estebaranz JL. Squamous cell carcinoma of the lip: a retrospective study of 146 patients. J Eur Acad Dermatol Venereol. 2012;26(9):1116-21. doi:10.1111/j.1468-3083.2011.04227.x

4. Salgarelli AC, Sartorelli F, Cangiano A, Pagani R, Collini M. Surgical treatment of lip cancer: our experience with 106 cases. J Oral Maxillofac Surg. 2009;67(4):840-5. doi:10.1016/j.joms.2008.09.020

5. Oliveira-Neto HH, Gleber-Netto FO, Sousa SF, França CM, Aguiar MC, Silva TA et al. A comparative study of
TAMs) macrophage markers more specifically identifies $\mathrm{TAMs}^{37}$ as done in the present study.

Taken together, the results of this study suggest the participation of TAMs in the modulation of immunoinflammatory responsesin themicroenvironment of SCCLL. The M2 subtype may be more important in early stages than in advanced stages of lip carcinogenesis. On the other hand, the progression of SCCLL does not seem to be related to an imbalance of macrophage polarization in the microenvironment of these tumors. These findings are important for a better understanding of the biological behavior of SCCLL. Investigation of the different inflammatory and non-inflammatory components present in the tumor microenvironment is needed to establish personalized and less mutilating treatments that would improve the quality of life of patients with this disease.

\section{Acknowledgment}

This study was supported by the following Brazilian funding agencies: Coordenação de Aperfeiçoamento de Pessoal de Nível Superior - CAPES (Edital Procad-NF; N²1/2009) and Conselho Nacional de Desenvolvimento Científico e Tecnológico - CNPq (Edital Universal; 485662/2012-4).

microvessel density in squamous cell carcinoma of the oral cavity and lip. Oral Surg Oral Med Oral Pathol Oral Radiol. 2012;113(3):391-8. doi:10.1016/j.tripleo.2011.08.010

6. Bilkay U, Kerem H, Ozek C, Gundogan H, Guner U, Gurler T et al. Management of lower lip cancer: a retrospective analysis of 118 patients and review of the literature. Ann Plast Surg. 2003;50(1):43-50. doi:10.1097/00000637-200301000-00008

7. Chen TC, Hsu CW, Lou PJ, Ko JY, Yang TL, Chen CN et al. The clinical predictive factors for subsequent distant metastasis in patients with locoregionally advanced oral squamous cell carcinoma. Oral Oncol. 2013;49(4):367-73. doi:10.1016/j.oraloncology.2012.10.006

8. Aquino AR, Carvalho CH, Nonaka CF, Freitas RA, Souza LB, Pinto LP. Immunoexpression of claudin-1 and Nm23-H1 in metastatic and nonmetastatic lower lip squamous-cell carcinoma. Appl Immunohistochem Mol Morphol. 2012;20(6):595-601. doi:10.1097/PAI.0b013e3182505c22

9. Eiro N, Vizoso FJ. Inflammation and cancer. World J Gastrointest Surg. 2012;4(3):62-72. doi:10.4240/wjgs.v4.i3.62 
10. Mantovani A, Sica A. Macrophages, innate immunity and cancer: balance, tolerance, and diversity. Curr Opin Immunol. 2010;22(2):231-7. doi:10.1016/j.coi.2010.01.009

11. Sica A, Larghi P, Mancino A, Rubino L, Porta C, Totaro MG et al. Macrophage polarization in tumour progression. Semin Cancer Biol. 2008;18(5):349-55. doi:10.1016/j.semcancer.2008.03.004

12. Baay M, Brouwer A, Pauwels P, Peeters M, Lardon F. Tumor cells and tumor-associated macrophages: secreted proteins as potential targets for therapy. Clin Dev Immunol. 2011;2011:565187. doi:10.1155/2011/565187

13. Cassetta L, Cassol E, Poli G. Macrophage polarization in health and disease. ScientificWorldJournal. 2011;11:2391-402. doi:10.1100/2011/213962

14. Costa NL, Valadares MC, Souza PP, Mendonça EF, Oliveira JC, Silva TA et al. Tumor-associated macrophages and the profile of inflammatory cytokines in oral squamous cell carcinoma. Oral Oncol. 2013;49(3):216-23. doi:10.1016/j.oraloncology.2012.09.012

15. Fujii N, Shomori K, Shiomi T, Nakabayashi M, Takeda C, Ryoke Ket al. Cancer-associated fibroblasts and CD163-positive macrophages in oral squamous cell carcinoma: their clinicopathological and prognostic significance. J Oral Pathol Med. 2012;41(6):444-51. doi:10.1111/j.1600-0714.2012.01127.x

16. Gordon S. The macrophage: past, present and future. Eur J Immunol. 2007;37(Suppl 1):S9-17. doi:10.1002/eji.200737638

17. Ma J, Liu L, Che G, Yu N, Dai F, You Z. The M1 form of tumor-associated macrophages in non-small cell lung cancer is positively associated with survival time. BMC Cancer. 2010;25(10):112. doi:10.1186/1471-2407-10-112

18. Martinez FO, Helming L, Gordon S. Alternative activation of macrophages: an immunologic functional perspective. Annu Rev Immunol. 2009;27(1):451-83. doi:10.1146/annurev.immunol.021908.132532

19. Merry R, Belfield L, McArdle P, McLennan A, Crean S, Foey A. Oral health and pathology: a macrophage account. Br J Oral Maxillofac Surg. 2012 Jan;50(1):2-7. doi:10.1016/j.bjoms.2010.10.020

20. Shapiro H, Lutaty A, Ariel A. Macrophages, meta-inflammation, and immuno-metabolism. ScientificWorldJournal. 2011;11:2509-29. doi:10.1100/2011/397971

21. Sica A. Role of tumour-associated macrophages in cancer-related inflammation. Exp Oncol. 2010;32(3):153-8.

22. Sica A, Porta C, Morlacchi S, Banfi S, Strauss L, Rimoldi M et al. Origin and functions of tumor-associated myeloid cells (TAMCs). Cancer Microenviron. 2012;5(2):133-49. doi:10.1007/s12307-011-0091-6

23. Li C, Shintani S, Terakado N, Nakashiro K, Hamakawa H. Infiltration of tumor-associated macrophages in human oral squamous cell carcinoma. Oncol Rep. 2002;9(6):1219-23.

24. Liu SY, Chang LC, Pan LF, Hung YJ, Lee CH, Shieh YS. Clinicopathologic significance of tumor cell-lined vessel and microenvironment in oral squamous cell carcinoma. Oral Oncol. 2008;44(3):277-85. doi:10.1016/j.oraloncology.2007.02.007
25. Marcus B, Arenberg D, Lee J, Kleer C, Chepeha DB, Schmalbach CE et al. Prognostic factors in oral cavity and oropharyngeal squamous cell carcinoma. Cancer. 2004;101(12):2779-87. doi:10.1002/cncr.20701

26. Zhang QW, Liu L, Gong CY, Shi HS, Zeng YH, Wang XZ et al. Prognostic significance of tumor-associated macrophages in solid tumor: a meta-analysis of the literature. PLoS One. 2012;7(12):e50946. doi:10.1371/journal.pone.0050946

27. Sobin LH, Wittekind C. TNM classification of malignant tumors. 6th ed. New Jersey: John Wiley \& Sons; 2002.

28. Bryne $M$. Is the invasive front of an oral carcinoma the most important area for prognostication? Oral Dis. 1998;4(2):70-7. doi:10.1111/j.1601-0825.1998.tb00260.x

29. Silveira EJ, Miguel MC, Lima KC, Freitas RA, Morais ML, Queiroz LM. Analysis of local immunity in squamous cell carcinoma of the tongue and lower lip. Exp Mol Pathol. 2010;88(1):171-5. doi:10.1016/j.yexmp.2009.11.009

30. Liu J, Zhang N, Li Q, Zhang W, Ke F, Leng Q et al. Tumor-associated macrophages recruit CCR6+ regulatory $\mathrm{T}$ cells and promote the development of colorectal cancer via enhancing CCL20 production in mice. PLoS One. 2011;6(4):e19495. doi:10.1371/journal.pone.0019495

31. Kryczek I, Zou L, Rodriguez P, Zhu G, Wei S, Mottram $\mathrm{P}$ et al. B7-H4 expression identifies a novel suppressive macrophage population in human ovarian carcinoma. J Exp Med. 2006;203(4):871-81. doi:10.1084/jem.20050930

32. Kuang DM, Zhao Q, Peng C, Xu J, Zhang JP, Wu C et al. Activated monocytes in peritumoral stroma of hepatocellular carcinoma foster immune privilege and disease progression through PD-L1. J Exp Med. 2009;206(6):1327-37. doi:10.1084/jem.20082173

33. Gasparoto TH, de Souza Malaspina TS, Damante JH, Melo Jr EF, Ikoma MR, Garlet GP et al. Regulatory T cells in the actinic cheilitis. J Oral Pathol Med. 2014;43(10):754-60. doi:10.1111/jop.12207

34. Geissmann F, Dieu-Nosjean MC, Dezutter C, Valladeau J, Kayal S, Leborgne $\mathrm{M}$ et al. Accumulation of immature Langerhans cells in human lymph nodes draining chronically inflamed skin. J Exp Med. 2002;196(4):417-30. doi:10.1084/jem.20020018

35. Nakamura H, Saji H, Aute I, Kawasaki N, Hosaka M, Ogata A et al. Peripheral leukocytes with HLA-DR+/CD8- phenotype are associated with prognosis in patients with lung cancer. Anticancer Res. 2003;23(5b):4149-52.

36. Maniecki MB, Møller HJ, Moestrup SK, Møller BK. CD163 positive subsets of blood dendritic cells: the scavenging macrophage receptors CD163 and CD91 are coexpressed on human dendritic cells and monocytes. Immunobiology. 2006;211(6-8):407-17. doi:10.1016/j.imbio.2006.05.019

37. Wada N, Zaki MA, Hori Y, Hashimoto K, Tsukaguchi $\mathrm{M}$, Tatsumi $\mathrm{Y}$ et al. Tumour-associated macrophages in diffuse large B-cell lymphoma: a study of the Osaka Lymphoma Study Group. Histopathology. 2012;60(2):313-9. doi:10.1111/j.1365-2559.2011.04096.x 